\title{
Directions for Contributors to WEED SCIENCE
}

Manuscripts about weeds or related topics will be considered for publication in WEED SCIENCE when at least one author is an active member of WSSA. Each manuscript should contain original material that constitutes a logical unit of related subject matter; progress reports are not acceptable. Each acceptance is made with the understanding that the manuscript has not been and will not be submitted in total or part for publication elsewhere without prior approval of the Editor of this Journal. However, prior publication in abstract form is permitted.

The Council of Biology Editors prepared and published the "Style Manual for Biological Journals". In most respects, WEED SCIENCE follows the recommendations in the latest edition of that Manual, including abbreviations, except when in conflict with these directions or the latest report of the WSSA Terminology Committee.

Manuscripts. Reference to a recent issue of WEED SCIENCE as a guide in preparing the manuscript is suggested. Each manuscript should be submitted to the Editor in duplicate on 21.6 by $27.9-\mathrm{cm}$ bond paper with lines numbered on each page. If paper with numbered lines is not available, number the lines consecutively from the top of the page and type the number of each line adjacent to it in the left margin. Two copies of all figures also are required. DOUBLE SPACE everything-title, abstract, text, footnotes, literature citations, captions, and tables. Capitalize the first letter of the first word and of major words in the title and section headings; however, sub-section headings should be in lower case letters entirely except the first letter of the first word and proper nouns. Begin sub-section headings at the left margin-do not indent. Number all pages consecutively. An additional copy of the manuscript should be retained by the author to insure against loss.

Use a title as short as practical, preferably one with a maximum of 50 characters. The author's name(s) should follow the title; the abstract should begin immediately thereafter on the same page before the beginning of the text. The text should be divided into sections, usually with such headings as Introduction, Methods and Materials, Results, and Discussion; Results and Discussion often may be combined into a single section. Do not include a summary or list of conclusions. The sequence of items in the assembled manuscript should be: Title and authors (no separate title page); Abstract; Text; Literature Cited (begin new page); Tables; Captions for figures; and Figures.

Do not underscore anything except Latin names of plants and animals, and subheadings within sections. Measurements, such as time, weight, and degrees, should be in arabic numerals regardless of the number of digits in each number, except as the first word of a sentence. When not one of measurement, figures below 10 should be spelled out except when one figure in a series has two or more digits, in which instance all should be in arabic numerals. The exclusive use of metric units of measurement is required.

The first mention of a herbicide should include the full chemical name followed immediately by the common name or designation in parentheses; only the common name or designation should be used thereafter. Only common names or designations as shown on the outside back cover of the current issue of WEED SCIENCE should be used. Trade names should be excluded.

The complete Latin name of all organisms should be underlined and shown in parentheses immediately following the common name when first mentioned. Such designations of crop plants should include the cultivated variety (cultivar) after the Latin name; e.g., corn (Zea mays L. 'Dixie 18'). Thereafter, only the common name should be used; indicate the cultivar name in single quotes as required for cultivar identification. Nomenclature of weeds should agree with that presented by the WSSA Terminology Committee in WEEDS 14:347-386, 1966; standard taxonomic authorities should be used as a guide in selection of terminology for other plants and all animals. Do not repeat the chemical name for herbicides or the Latin name for plants and animals in the text if they have been given in the abstract. Use common name or designation for herbicides and the common name for weeds or well known crops in the title of the manuscript.

Footnotes. Use footnotes sparingly. The title should refer to footnote 1 which should be or begin with "Received for publication - The place where the study was conducted and the title and address of the author(s) should be given, including zip code, as footnotes at the bottom of the first page. These and subsequent footnotes to the text should be numbered consecutively throughout the manuscript with superscript arabic numerals.

Acknowledgments. Acknowledgments should be given in a text section at the end of the text and before the Literature Cited section rather than in footnotes.

Figures. Experimental data may be presented in graphic or tabular form, but the same data will not be published in both forms. Figures will be published only when they convey an essential concept that can not be done adequately by words or numbers. Place the author's name(s) and figure number on the back of each figure and then enclose all figures in an envelope also bearing the author's name(s). Never fasten figures to paper by paper clips or staples. Photographs should be clear, black and white, glossy prints trimmed of unessential portions. All legends for figures should be typed on one sheet separate from the figures, and double spaced. Figures should be numbered consecutively in arabic numerals in the sequence of first reference in the text. Figures will be published at the maximum width of one journal column $(8.5 \mathrm{~cm})$, unless authorized otherwise by the Editor; figure preparation should allow for such reduction in size without loss of clarity or legibility.

Tables. Type each table double-spaced on a separate sheet. Inside long tables, the lines may be single spaced but not the captions. Tables should be numbered in arabic numerals in the sequence of first reference in the text. However, first reference to tables included primarily to present results should be in the Results section. The caption, column headings, and side headings of each table should be in lower case letters with only the first word and proper nouns capitalized. Avoid reporting non-significant decimal places. Data reporting average values should be analyzed statistically and the results of the analysis included in the table. The unit of measurement in a column of figures should be abbreviated and placed in parentheses at the top of the column under the solid horizontal line. When this value is other than unity, place the modifier ahead of the unit; i.e., $\left(10^{-4} \mathrm{M}\right)$. Footnotes to tables should be designated with superscript lower case letters.

Literature Cited. Citations are numbered alphabetically by senior author, and the number of the reference is used in the text. Each citation should include names of all authors, year of publication, complete title, publication, volume number, and inclusive pages, in that sequence. When two or more authors are listed, initials should follow the last name for the first, but the initials should precede the last name of the second and additional authors (See detailed directions in the Style Manual). Theses, letters, or other communication or publication not normally available in libraries should appear as text footnotes and not in the Literature Cited section.

Abstract. An abstract must follow the title and name(s) of the author(s) on page 1 of each manuscript. It should be a noncritical, informative digest of the significant content and conclusions of the paper, not a mere description of or reference to contents of the text. It should be intelligible without reference to the original text. It should be brief (length preferably less than $3 \%$ of the total manuscript), written in whole sentences rather than telegraphic phrases. The abstract should omit titular information, tables, graphs, detailed descriptions of experiments, and long lists of names. 


\section{Common and Chemical Names of Herbicides ${ }^{\mathrm{a}}$}

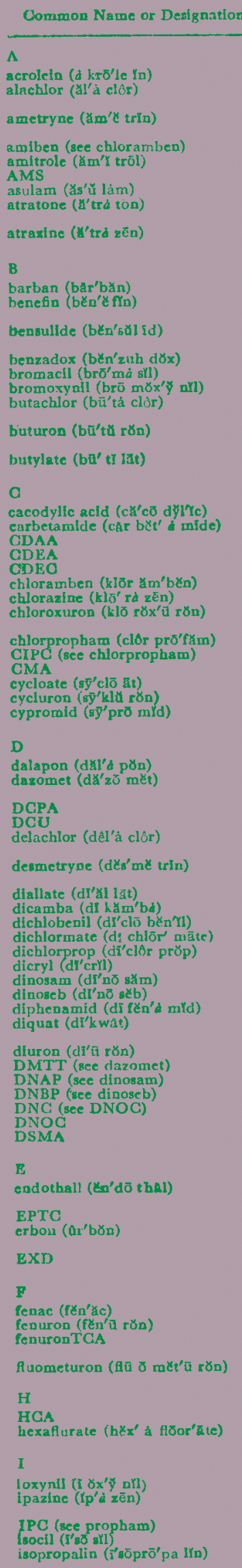

Chemical Nameb

acrolein

2-chloro-2', 6'-diethyl- $\mathcal{N}$ -

(methoxymethyl) acetanilide

(ethylamino) -4-(isopropylamino) -6-

3-amino-s-triazole

3-amia-s-triasole

methyl sulfanilylcarbamate

2-(ethylanino) -4 (isopropylamino) -6-methoxy-

2-chloro-4-(ethylamino)-6-(Isopropylamino)-

s-triazine

4-chloro-2-butynyl m-chlorocarbanilate

$\mathcal{N}$-butyl- $\mathcal{N}$-ethyl- $a, a, a$, -trifluoro-2, 6-dinitro- $\rho$ -

0,0 -diisopropyl phosphorodithioate $S$-ester with

$\mathcal{N}$-(2-mercaptoethyl) benzenesulfonamide

(benzamidooxy) acetic acid

5-bromo-3-sec-butyd-6-methyluracil

3,5-dibromo-4-hydroxybenzonitril

$\mathcal{N}$-(butoxymethyl)-2-

3-(p-chlorophenyl)-1-methyl-1-(1-methyl-2.

propynyl) urea

S-ethyl dilsobutylthiocarbamate

hydroxydimethylarsine oxlde

$D$ - $\mathcal{N}$-ethyllactamide carbanilate (cster)

$N_{n}, N$-diallyl-2-chloroacetamlite

2-chloro- $\mathcal{N}, \mathcal{N}$-diethylacetamide

2-chloroallyl dicthyldithlocarbamate

3-amino-2,5-dichlorobenzolc acid

2-chloro-4,6-bis (diethylamino)-s-triazine

3- $\{p$-(p-chlorophenoxy) phenyl $\}-1,1$-dimethyl $=$

urea
isopropyl m-chlorocarbanilate

calclum methanearsonate

S-ethyl N-ethylthiocyclohexanecarbamate

3-cycloactyl-1,1-dime thylure

$3^{\prime}, 4^{\prime}$-dichlorocyclopropanecarboxanllide

2,2-dichloroproplonic acld
tetrahydro-3,5-dimethyl-2H-1,3,5-thtadiazine-

2-1hlone
dimetlyl tetrachloroterephthalate

1,3-bis (2,2,2-trichloro-1-hydroxyethyl) urea

2-chloro- $\mathcal{N}$-(isobutoxymethyl)-2', $6^{\prime}$.

2-(isopropylamino)-4-(methylamino)-6-

(methylthlo)-s-triazine

$S$-(2,3-dichloroallyl) dilsopropylthiocarbamate

3,6-dichloro-0-anisic acid

2,6-dichlorobenzonitrile

3,4-dichlorobenzyl methylcarbamate

2-(2,4-dichlorophenoxy) propionic aci

$3^{\prime}, 4^{\prime}$-dichloro-2-methylacrylanilide

2-(1-methylbutyl)-4,6-dinitropheno

2-se6-butyl-4,6-dinitrophenol

N,N-dimethyl-2,2-diphenylacetamide

6,7 -dihydrodipyrido $\left[1,2-\alpha: 2^{\prime}, 1^{\prime}-c\right]$ pyrazinedi $=$

3-(3,4-dichloropheny1)-1,1-dimethylurea

4-dinitro-e-cregol

disodium methanearsonate

7-oxabicyclo[2.2.1]heptane-2,3-dicarboxyllc

acid -cthyl dipropyltblocarbamate

2-(2,4,5-trichlorophenoxy)ethyl 2,2-dichloro =

o,O-diethyl dithiobia[thoformate]

(2,3,6-trichlorophenyl)acetic acid 1,1-dimethyl-3-phenylures

1,1-dimethyl-3-phenylurea mono(trichloro $=$

1,1-dimethyl-3-(a,a,a,-trifluoro-m-tolyl) urea

1,1,1,3,3,3-hexachloro-2-propanone

potasaium bexafluoroarsenate

4-bydroxy-3,5-dijodobenzonitrile

2-chloro-4-(diethylamino)-6-(isopropylaraino)s-trazine

5-bromo-3-18opropyl-6-methyluraci

2,6-dinitro- $N, \mathcal{N}$-dipropylcumidine
Common Name or Designation

Chemical Nameb

K.

KOCN

potassium cyanate

lenacil (lěn'à eli)

3-cyclohe xyl-6, 7-dibydro- $1 H$-cyclopenta-

linuron (lYn'ū rön)

3-(3,4-dichlorophenyl)-1-methoxy-1-methylurea

M

MAA

MAMA

MCPA

MCPB
MCPFS

MCPP (see mecoprop)

mecoprop (m飞c'o prop)

metham (meth'an

metobromuron (mét' $\delta$ broma'u rŏn)

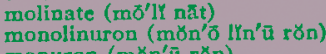

monuronTCA

MSMA

nuptalam (napptálym)

neburon (nzb/a ron)

vitralin (ni'trd lin)

nitrofen ( $n \bar{n}^{\prime}$ tro $f(x)$

norea (no rత్ర $u$ )

NPA (see naptalam)

0

oryzalin ( $8 r^{\prime} x: 4$ IIn)

P

paraquat (par $k w a t)$

PBA

pebulate (p̌rb'a lat

phenmedipham (fen med'i fam)

picloram (plc'lor àm)

PMA

prometone (prō'me tठีก)

prometryne (prós mo trín)

propacblor (própd clôr)

propanil (própd nłl)

propazine (pro'pd zén)

propham (pro tam

pyriclor (píry clor)

selone (Bะáon)

siduron (gld a $r$ ron)

silvex (sIt'veylks)

simazine (sไm's z区्En)

simetone (sim' ton)

simetryne (sim' trin)

solan (són 1 Ian)

swep (swěp)

$\mathbf{r}$

terbacll (tốr'bi cill)

terbutryn (t'tr'bu trîn)

TCA

triallate (trì' kl lăt)

tricamba (trí cxampd)

trictaxine (tri \&t' \& zẻn)

trifluralin (trī flar'd IYn)

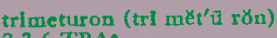

$2,3,6-\mathrm{TBA}^{\circ}$

$2,4-\mathrm{D}$

2,4-DB

2,4-DEB

2,4-DP (see dichlorprop)

$2,4,5-7^{\circ}$
$2,4,5-$ TES

$\checkmark$

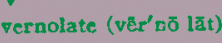

methanearsonic acid

monoammonium methanearsonat

[(4-chloro-tolyl) oxy] acetic acid

$2-[(4-c h l o r o-\theta-t o l y\})$ oxy $]$ ethyl sodium sulfate

2-[(4-chloro-o-toly])oxy]proplonic acld

dium methyldithiocarbamate

3-( $p$-bromophenyl)-1-methoxy-1-methylurea

,2-dihydro-3,6-pyridazinedione

-ethyl hexahydro-1/A-azepine-1-carbothloate

- ( $p$-chlorophenyl) -1-methoxy-1 -methylurea

3-( $p$-chlorophenyl)-1,1-dimethylure

mono(trichloroacetate)

monosodium methanearsonate

V-1-naphthylphthalamic acld

1-butyl-3-(3,4-dichlorophenyl)-1 - methylurea

4-(methylsulfonyl)-2,6-dinitro- $N, N$ -

2,4-dichlorophenyl -nitrophenyl ether

3-(hexahydro-4, 7-methanoindan-5-yl)-1,1-

dimethylurea

3,5-dinitro- $\mathcal{N}_{3}, \mathcal{N}^{2}$-dipropylaulfanilanalde

1,1'-dimethyl-4,4'-blpyridinlum ion

chlorinated benzole acid

p-propyl butylethylthlocarbamate

methyl m-hydroxycarbanilate $m$-methylcar $=$

banilate

4-mino-3,5,6-trichloroplcolinic acid

(acetato) phenylmercur

4-bis (inopropylamlao -6-methoxy-s-triagln

4-bis(isopropylamino ) -6-(methylthio)- \&-

-chloro-N-1sopropylacetanllide

4'-dichloroproplonanilid

-chloro-4,6-bis (3iopropylamino)-s-trlazine

isopropyl carbanilate

2,3,5-trichloro-4-pyridino

2-(2,4-dichlorophenoxy)ethyl sodlum sulfate

1- (2-metbyleyclohexyl)-3-phenylure

2-(2,4,3-trichlorophenoxy) propionic acld

2-chioro-4,6-bis(ethylamino)-r-triataine

2,4-bis(ethylamino)-6-(methylthio)-m-trimzine

3 -chloro-2-methyl-p-valerotoluidide

methyl 3,4-dichlorocarbsnilate

3-tert-butyl-5-chloro-6-metbyluracl!

2, (tart-butvlamion)-4- - methylearbamate (ethylamino)-6-

(racthyl thio)-s- triazine

s. $(2,3,3$-trichloroally!

dilisopropylthiocarbamate

3,5,6-trichloro-a-anisic acid

2-chloro-4-(diethylamino)-6-(ethyla mino)-s-

$a, a, a$, trifluoro-2,6-dinitro- $\mathcal{N}, \mathcal{N}$-dipropyl-p-

toluidine

1-( $p$-chlorophenyl)-2,3,3-trlmethylpseudourea

2, 3,6-trichlorobenzolc acid

(2,4-dichlorophenuzy) acetic acld

4-(2,4-dichlorophenoxy) butyric acld

2-(2,4-dichlorophenoxy)ethyl benzoate
tris 2 -(2,4-dichlorophenoxy)ethyl] phosphite

(2,4,5-trichlorophenoxy)acetic acld

sodium $2-(2,4,5-$ trichlorophenoxy)ethyl sulfate

S-propyl dlpropylthlocarbamate

-Herblcides no longer in use in USA are omitted. Complete listing, fneluding hese, is in WEEDS 14(4), 1966.

bAs tabulated in an equal $(=)$ sign is joined together without any separation if written on one line

- This herbiclde usually is available an mixed tsomers. When posible, the isomers should be Identified, the amount of each isomer in the mixture specifed and the source of the experimental chemicals given. 